\title{
EXPERIMENTAL INVESTIGATION OF R-134a AND R-600a REFRIGERANT BLEND IN DOMESTIC VAPOUR COMPRESSION REFRIGERATION SYSTEM
}

\author{
M. E. Uwadiae ${ }^{1,}$, M. A. Akintunde ${ }^{2}$ and T. I. Ogedengbe ${ }^{3}$ \\ 1,2,3 Dept. of Mechanical Engineering, Federal University of Technology, AKure, Ondo State. NigERIA \\ Email addresses:1 uwasme@yahoo.com,2ajyinka@yahoo.com,33tioged@yahoo.com
}

\begin{abstract}
The refrigeration industry today needs refrigerants with global warming potential (GWP) $\leq 150$ according to the European Union protocol, alongside other properties, which no single refrigerant has met as at today. This study focused on blending of existing refrigerants towards obtaining blends with GWP $\leq 150$. It investigated the performance of blends of two existing refrigerant, $R-134 a$ and $R-600 a$, blended together at ratios of 11\%/89\%, 7.5\%/92.5\% and 3.6\%/96.4\% to form blends $K, L$ and $M$ respectively. The blends were to have, according to the blending ratios, estimated GWPs $\leq 150$ using Ali's model. The blends flammability was tested and the blends were then charged into domestic vapour compression systems, where their operating temperatures and pressures were obtained every 5 minutes during the experimentation. The flammability test shows they are flammable while results obtained at ambient temperatures $\left(37^{\circ} \mathrm{C}, 32^{\circ} \mathrm{C}\right)$ under same operating conditions indicated evaporator temperatures $\left(7.7^{\circ} \mathrm{C},-3.1^{\circ} \mathrm{C},-3.7^{\circ} \mathrm{C},-4.7^{\circ} \mathrm{C},-5.3^{\circ} \mathrm{C}\right) ;\left(6.2^{\circ} \mathrm{C},-3^{\circ} \mathrm{C},-4^{\circ} \mathrm{C},-4.8^{\circ} \mathrm{C},-6.5^{\circ} \mathrm{C}\right)$ for $\mathrm{R}-134 \mathrm{C}, \mathrm{K}, \mathrm{L}, \mathrm{M}$ and $\mathrm{R}-600 \mathrm{a}$ respectively. Also the analysis of the results gave corresponding average Coefficient of Performance (COP) of $(0.8389,1.0708,1.0898$, 1.1181 , and 1.1373) and $(0.8283,1.0923,1.1254,1.1579$ and 1.2159) for the aforementioned respective refrigerants at ambient temperatures of $37^{\circ} \mathrm{C}$ and $32^{\circ} \mathrm{C}$, respectively. Thus, the blends can replace $R-134 a$ without changing pipe, cooling method and lubricants and still obtain higher COP, though mildly flammable-having slow burning velocity and low heat of combustion. That blend $K$ offers significant improvement in flammability compared to $R-600 a$ alongside higher COP to R-134a, makes it the best alternative of the blends.
\end{abstract}

\section{Keywords: Coefficient of Performance (COP), Vapour Compression Refrigeration System, Flammability, Global warming Potential (GWP), Refrigerant, Refrigerant blend.}

\section{INTRODUCTION}

Refrigeration is the extractions of heat from a low temperature body to that at higher temperature [1]. This is possible due to the evaporation of a working fluid known as refrigerant flowing through sequentially arranged mechanical components forming a refrigeration system [2]. The refrigerant plays a vital role of heat circulation in a refrigeration system and forms the bed rock of the industry [3]. Different refrigerants have been developed due to various developmental challenges (of toxicity, ozone depletion) up till today's challenge of GWP, prompting the need of a new refrigerant of GWP $\leq 150$. Refrigerant having GWP $>150$ forms a shield reflecting excess ultra-violet rays to the earth, thus, increasing its temperature above normal for her living inhabitants [4]. The difficulty of finding a single chemical refrigerant that can satisfy the required GWP has led to blend formation [5,6].The research objective is to develop a refrigerant blend of GWP $\leq 150$ and experimentally observe its performance in a domestic vapour compression refrigerating system if it is worthy of replacing R-134a whose shortcoming is its high GWP.

The earth's temperature is controlled by the amount of sun's energy received and reflected [4]. Though smoke and other emissions resulting from fuel wood in traditional stoves have led to increase in health hazards and earth's temperature among others, researchers have made several effort to improve the situation through biomass fuel and stoves $[7,8]$. However, greenhouse gases, refrigerant inclusive, have been found to reflect infrared rays to the earth, thus, increasing its temperature. To prevent this awkward rise in temperature capable of making the earth inhabitable, the European Union has proposed the ban of refrigerants having GWP $>150$ [9]. Though several

* Corresponding author, tel: +234-805-522- 1146 
refrigerants (non synthetic; $\mathrm{CH}_{4}$ and synthetic; $\mathrm{R}-152 \mathrm{a}$ ) have GWP $<150$, they are either flammable, toxic, ozone depletive or have high operating pressures, hence, the need for a new refrigerant. The difficulty of finding a single chemical refrigerant devoid of these limitations, has led to blend consideration; as new refrigerant of desired properties can be developed by mixing two or more single refrigerants $[10,11]$. This has since form a path way in the search of that ideal refrigerant for the replacement of R-134a, being the predominant refrigerant use in the domestic refrigeration industry even though R-22 is still been used [12].

Wongwise and Chimres[13], reported an experimental study on the application of a mixture of propane, butane and isobutene to replace R-134a. The results showed that a $60 \% / 40 \%$ propane/butane mixture was the most appropriate alternative refrigerant. Also, Wongwise et al. [14] presented an experimental study on the application of HC mixture, to replace R-134a and they found that propane/butane/isobutene at $50 \% / 40 \% / 10 \%$ was the best alternative refrigerant to replace it. Having the best performance of all other mixture been investigated. A trial was also made by Khorshid et al. [15] to replace R-134a by two different blends: one as R-134a (6.61\%), R-32 (5.64\%) and R152a (87.75\%); and the other as R-32 (15.34\%), R600a (8.79\%) and R-152a (75.87\%). The results of the test shows that COP improved by $11.93 \%$ and $2.07 \%$ using the former and latter respectively as compared with R-134a; with the new refrigerant blends having zero ozone depletion potential (ODP) and low GWP of the order of 242 and 200 respectively. Austin, et al. [16] investigated a propane-butane mixture and found that the refrigerator worked efficiently when mixed refrigerant was used as refrigerant instead of R-134a.

Analysis of the above researches shows that though performance is enhanced, the resulted blends are either highly flammable or they have GWP exceeding the preferred optimum, thus, prohibiting their usage as define by the European Union. Therefore, the focus of this study is on developing a blend within the preferred GWP limit and considering its performance in the system. Ali's model [17] for estimating the GWP of blend when those of the individual refrigerants are known could be used to determine the ratio that will form a blend within the European Union's GWP limits. Since blends of HFC and HC has been reported to produce new refrigerant capable of overcoming their shortcomings of high GWP and flammability [11], R134a and R-600a were selected for having better nonflammability and low GWP respectively. Subsequently, three blends label K, L, and M with respective GWP of 150, 100 and 50 were formed, had their flammability tested and their performance investigated in a domestic vapour compression system

\section{METHODOLOGY}

The steps adopted in developing and investigating the blend are given as follows:

\subsection{Selection of the individual refrigerant making the blend}

Blending HFC and HC usually produces a new refrigerant overcoming their shortcoming of GWP and flammability respectively. The idea therefore, is to select an HFC refrigerant having good thermodynamic and thermo-physical properties, non-flammable, nontoxic and low GWP; and an HC refrigerant with low flammability to form the blend. Thus, since the alkane series are less flammable among other HCs and its flammability reduce down its group, butane was selected among its first four members, which are refrigerant gases. In the case of the HFC, though R-152a and R-32 have lower GWP but aside their flammability (being A2, as classify by ASHARE), their toxicity either in themselves or when combined with air during leakage makes them inconsiderable in this research as a domestic refrigeration system is to be used. Therefore, R-134a was considered, for its nonflammability and non-toxicity. The blend hence was a mixture of R-134a and R-600a.

It is assumed by this selection of R-134a and R-600a that the:

i. blend will have zero ozone depletion potential, since R-134a and R-600a are not ozone depleting substance couple with the non-presence of any ozone depleting atom; and

ii. blend will be non-toxic as R-134a and R-600a are non-toxic.

\subsection{Determination of blends composition ratio, that} ensures adherence to the preferred GWP limit.

Ali [17] reported the model for the estimation of the GWP of refrigerant blend when those of its individual refrigerants are known as shown in Eqn 1.

$$
\left(G_{1} P_{1} \times M_{1}\right)+\left(G W P_{2} \times M_{2}\right)=G W P_{b}
$$

Where: $\mathrm{GWP}_{1}$ is the global warming potential of refrigerant $1, \mathrm{GWP}_{2}$ is the global warming potential of refrigerant $2, \mathrm{GWP}_{\mathrm{b}}$ is the global warming potential of refrigerant blend, $\mathrm{M}_{1}(\%)$ is the mass percentage composition of refrigerant 1 in the blend, and $\mathrm{M}_{2}(\%)$ is the mass percentage composition of refrigerant 2 in the blend.

Equation (1) was used to estimate the mass composition ratio. The GWP of the blend were chosen as 150,100 and 50, with that of R-134a and R-600a as 
1300 and 3 respectively, the composition ratio was estimated as follows:

Let $(\mathrm{Q})$ be the mass composition of $\mathrm{R}-134 \mathrm{a}$ in the blend then, (1-Q) is the mass composition of R-600a

Therefore substituting the values into Eqn (1), we have:

For blend K: GWP $=150$

$(1300 \times Q)+(3 \times(1-Q))=150$ or $Q=0.11$

Thus, the mass composition ratio is $11 \% \mathrm{R}-134 \mathrm{a}$ and 89\% R-600a;

For blend L: GWP $=100$

$(1300 \times Q)+(3 \times(1-Q))=100$ or $Q=0.075$

Thus, the mass composition ratio is $7.5 \% \mathrm{R}-134 \mathrm{a}$ and 92.5\% R-600a; and

For blend M: GWP $=50$

$(1300 \times Q)+(3 \times(1-Q))=50$ or $Q=0.036$

Thus, the mass composition ratio is $3.6 \% \mathrm{R}-134 \mathrm{a}$ and 96.4\% R-600a.

\subsection{Flammability test by ignition}

Sample of the blends were allowed to leak out of the cylinder into a flame and their flammability were observed.

\subsection{Determination of operating temperatures and pressure}

The blends were charged into the compressor of the vapour compression refrigerating system and run, and the following parameters measured with the aid of thermometers and barometers:

i. evaporator temperature;

ii. condenser temperature; and

iii. compressor suction and discharge pressure which forms the operating pressure limit of the system.

\subsection{Evaluation of the coefficient of performance (COP)}

The blend has no standard characteristic chart as at now, therefore, the values of the operating temperatures and pressure obtained earlier on were used to evaluate the coefficient of performance of the system, using the Carnot cycle efficiency formula given in Eqn (2),

$$
\mathrm{COP}=\frac{\mathrm{T}_{\text {condenser }}-\mathrm{T}_{\text {evaporator }}}{\mathrm{T}_{\text {condenser }}}
$$

Where, $T_{\text {condenser }}$ is the temperature of the condenser, $T_{\text {evaporator }}$ is the temperature of the evaporator and (COP) is the coefficient of performance of the system.

\subsection{Details of the experimental procedure}

The required mass composition of blend $\mathrm{K}$ is $11 \%$ of $\mathrm{R}$ 134a and $89 \%$ of R-600a. In-order to achieve this, $1 \mathrm{~kg}$ of each of the refrigerant was bought. The blend $\mathrm{K}$ was formed in an empty cylinder whose mass was measured as $2482 \mathrm{~g}$, with the aid of a digital beam balance, by gradually injecting R-134a into the empty cylinder till 11\% (110 g) of the $1 \mathrm{~kg}$ entered, making its mass read $2592 \mathrm{~g}$ (i.e. $2482 \mathrm{~g}$ of the empty cylinder + $110 \mathrm{~g}$ of R-134a) on the beam balance. This was followed by further injecting $89 \%$ (i.e. $890 \mathrm{~g}$ ) of R-600a into the cylinder till the mass now read $3482 \mathrm{~g}$ (i.e. $2592 \mathrm{~g}+890 \mathrm{~g}$ ), making a total of $1 \mathrm{~kg}$ of the blend in the cylinder. The same procedure was followed to formulate blends L and $\mathrm{M}$.

After obtaining the blends, attempt was made to ignite a sample from them by allowing it leak into a flame to determine their flammability. Thereafter, the blends were each charged into the compressor of the vapour compression systems (see Figure 1). For comparison, same mass of R-134a and R-600a were also charged separately into compressor of similar systems, and were all run simultaneously at controlled ambient temperatures. Since an open system was chosen which cannot be loaded, the experiment was performed at ambient temperatures of $37^{\circ} \mathrm{C}$, and $32^{\circ} \mathrm{C}$ to observe the effect of the various temperatures on its characteristics.

To determine the operating temperatures and pressures, four thermometers were attached to each system's evaporator, condenser and compressor inlet and outlet to measure their respective temperatures while two barometers were attached to the inlet and outlet of the compressor to measure their operating pressures. The mass flow rates of the systems were set equal $(0.05 \mathrm{~kg} / \mathrm{s})$ and readings from the thermometers and barometers were obtained every 5 minutes during operation. This was replicated five times for each ambient temperature.

\section{RESULTS AND DISCUSSION}

Igniting of the samples showed that they are mildly flammable, though on close observation the rigour of their flammability (i.e. ease of ignition and rate of propagation) increases from blend $\mathrm{K}$ to $\mathrm{R}-600 \mathrm{a}$. This is due to the reduction in the mass composition of R-134a which hinders the flammability of R-600a in the mixture. While the mean of the results obtained during the experimental investigation of the blends alongside R-600a and R-134a when run simultaneously under same conditions are as shown in Figures 2 to 7. 


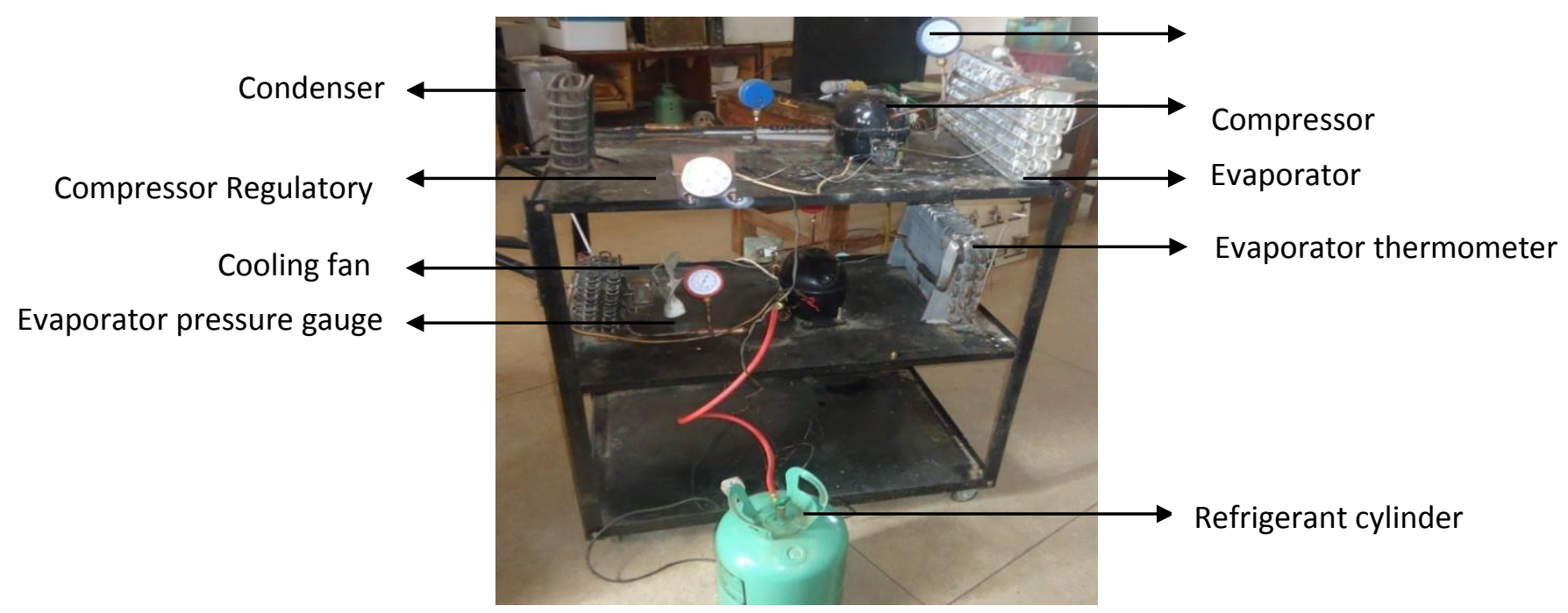

Figure 1: A typical setup for investigating the coefficient of performance of the refrigerants
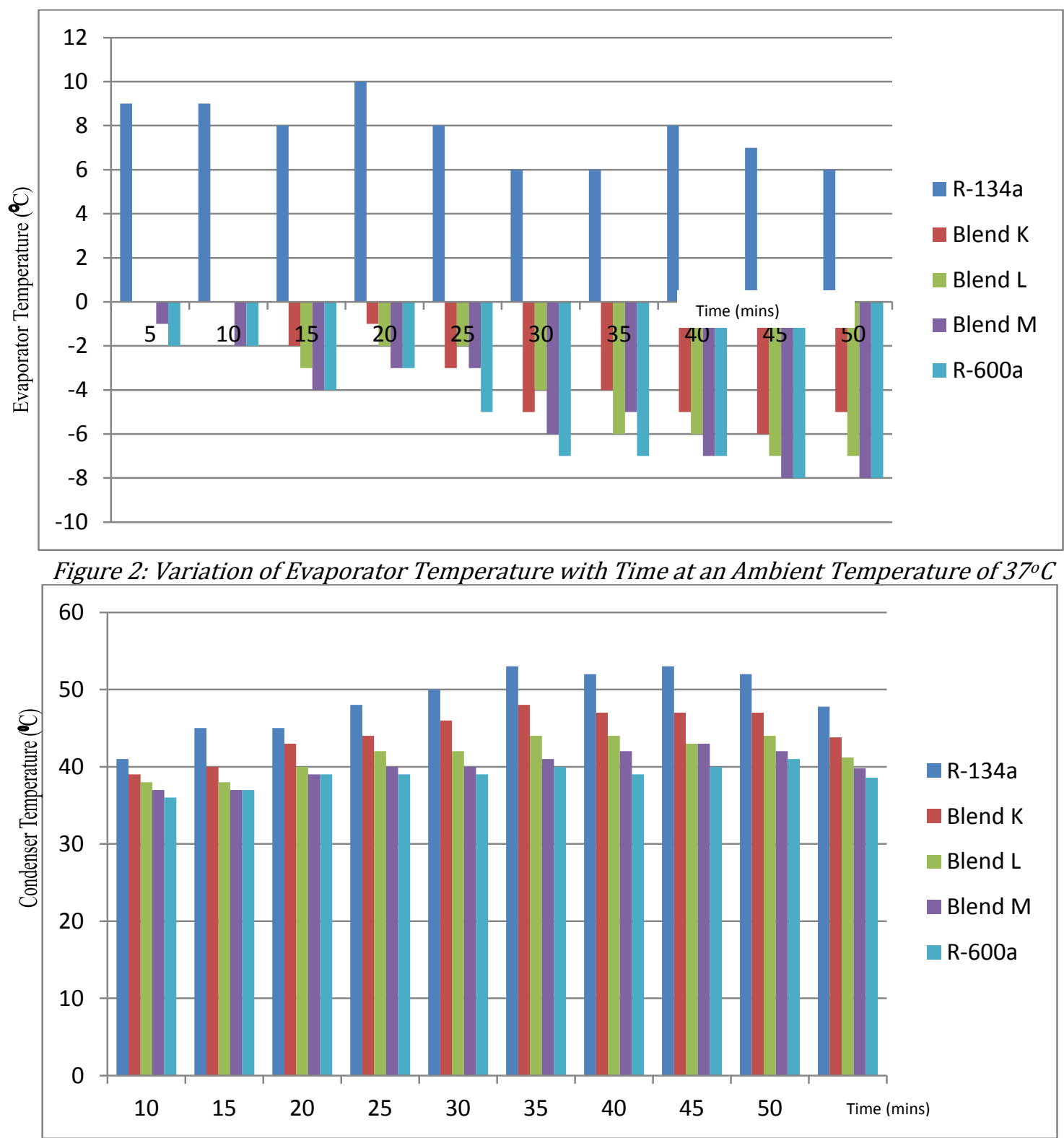

Figure 3: Variation of Condenser Temperature with Time at an Ambient Temperature of $37^{\circ} \mathrm{C}$ 


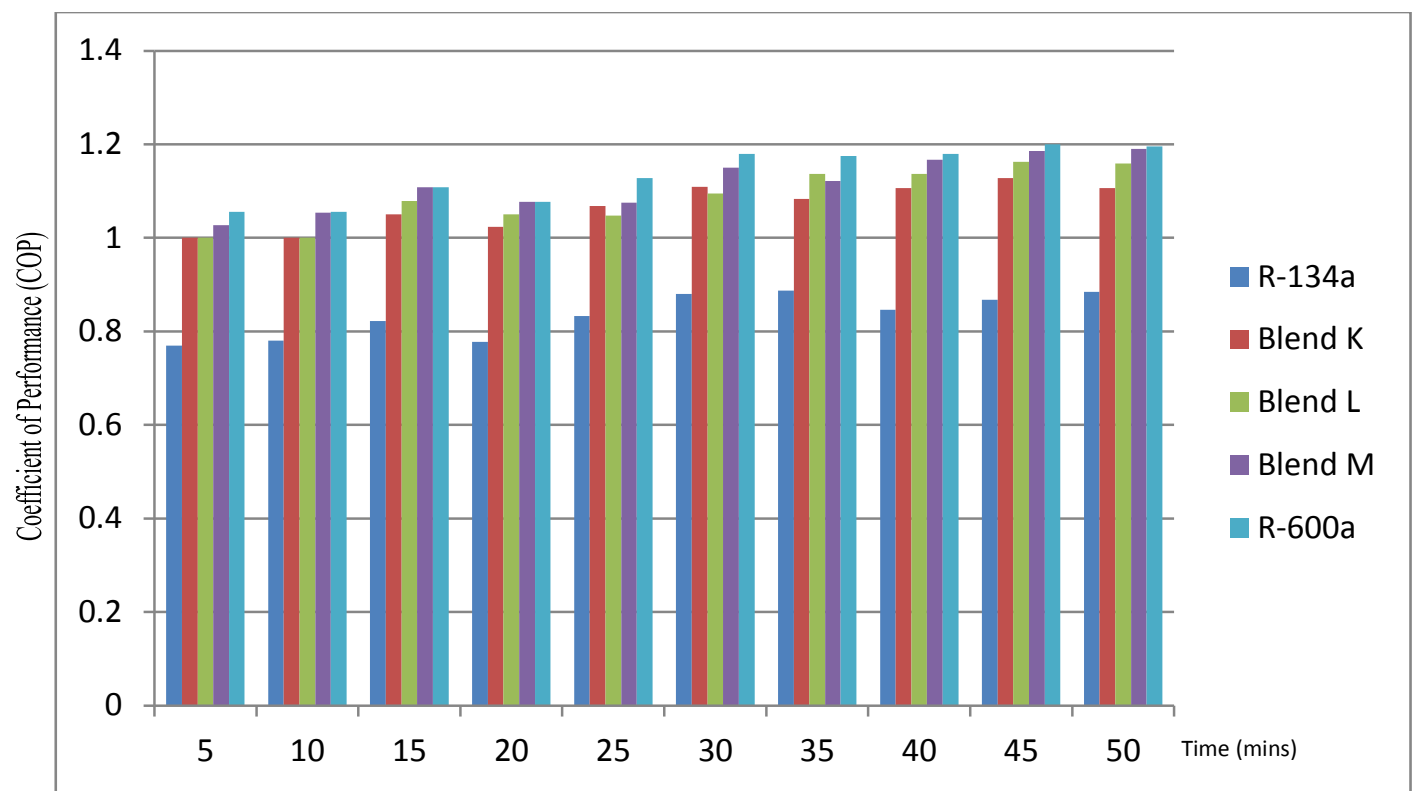

Figure 4: Variation of COP with Time at an Ambient Temperature of $37^{\circ} \mathrm{C}$

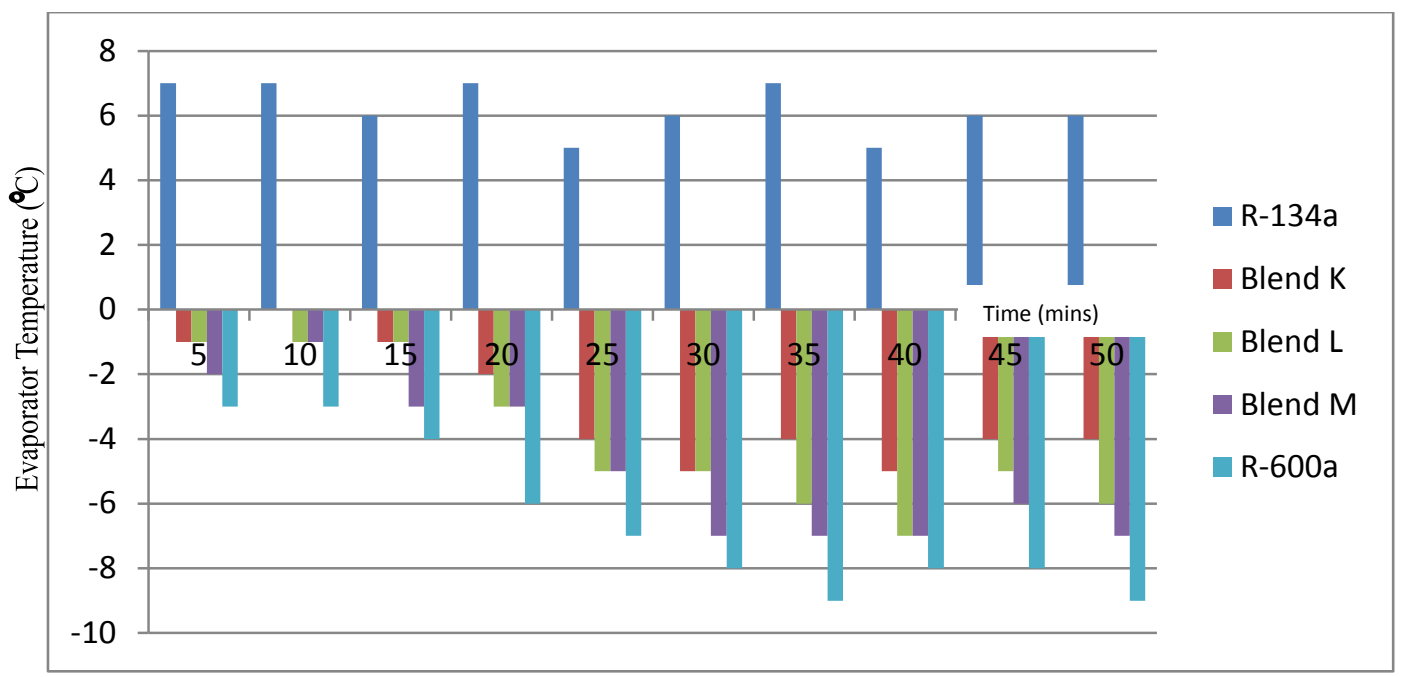

Figure 5: Variation of Evaporator Temperature with Time at an Ambient Temperature of $32^{\circ} \mathrm{C}$

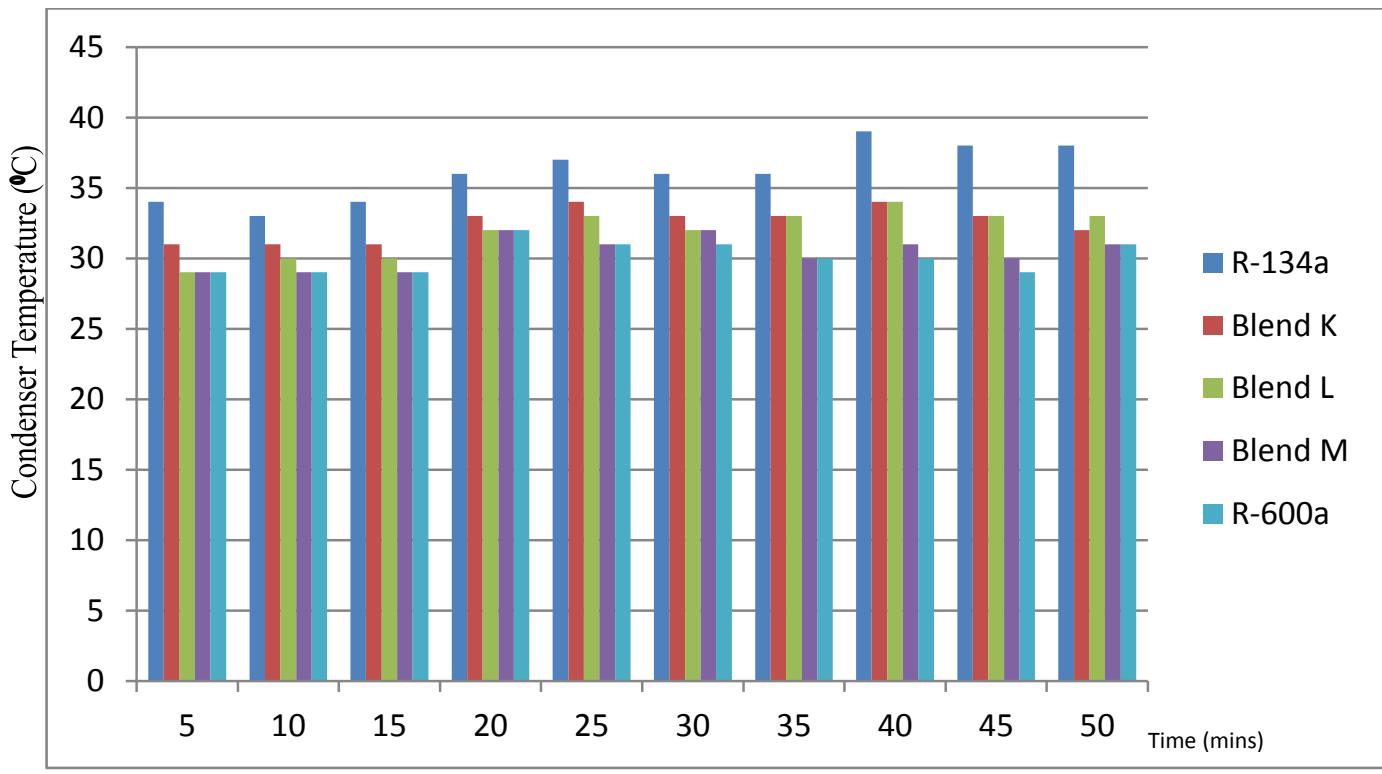

Figure 6: Variation of Condenser Temperature with Time at an Ambient Temperature of $32^{\circ} \mathrm{C}$ 


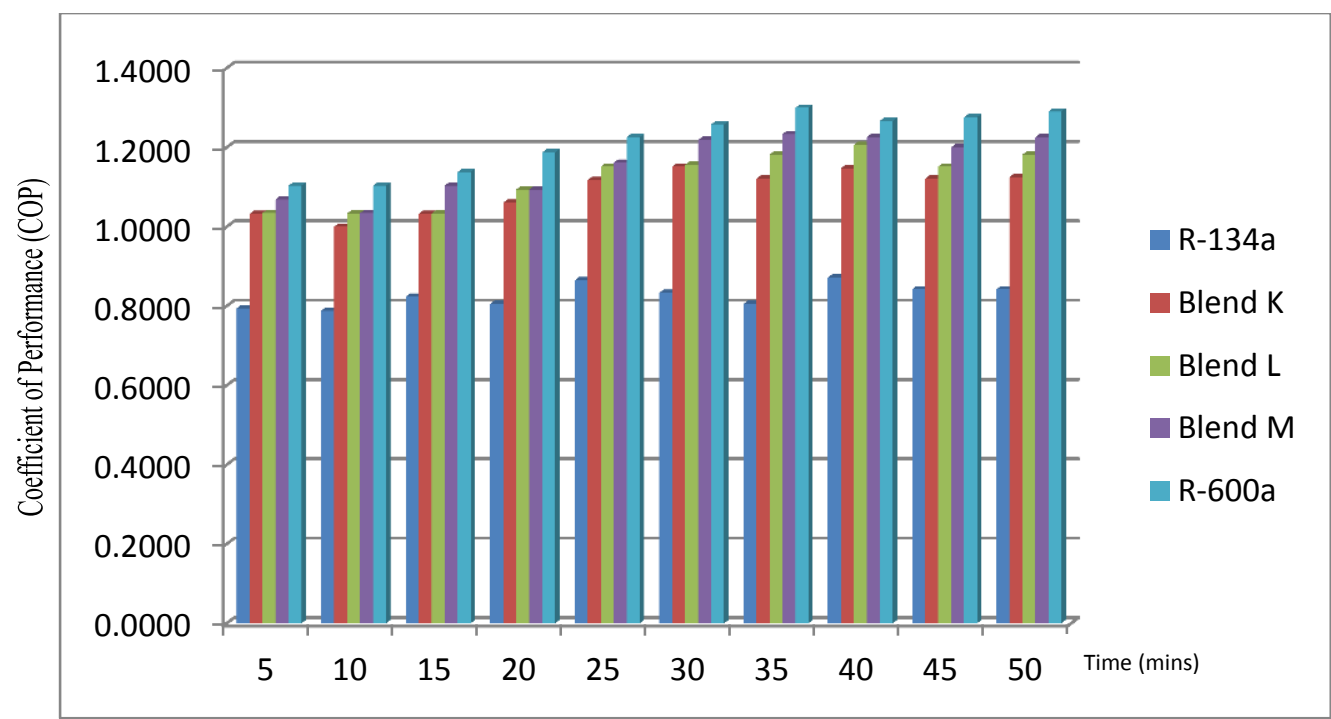

Figure 7: Variation at COP with Time at an Ambient Temperature of $32^{\circ} \mathrm{C}$

Analysis of the results as presented in Figures 2 to 7, indicate the following:

i. the COP of the refrigerants increases as the ambient temperature reduces;

ii. the COP of the refrigerants increases from R-134a ,blends $K, L, M$, to R-600a irrespective of the ambient temperature;

iii. the difference in COP is due to the ability of the blends to attained different evaporator and condenser temperatures;

iv. the evaporator, condenser and compressor's suction and discharge temperatures as well as the compressor's suction and discharge pressure decreases from R-134a to R-600a irrespective of the ambient temperature- The lower discharge temperature increases the life of the compressor; and

v. the pressure ratios of the refrigerants are significantly close having $(5.5,5.3,5.3,5.3,5.4)$ bars for R-134a to R-600a respectively, thus allowing similar pipe thickness in the system.

Based on the above observations, it could be inferred that the COP of the formulated refrigerants blends is higher than that of R-134a indicating that each of the blend exhibit higher performance with respect to R134a but lesser performance compared to R-600a. Therefore, the blends could be used in the place of R134a without affecting the operation efficiency of a vapour compression refrigeration system. It could also be observed from this study that blend K offers the best alternative when the COP and flammability are combined as performance metrics. This is because it has higher COP $(1.0708 ; 1.0923)$ compared to R-134a $(0.8389 ; 0.8283)$ at ambient temperatures of $37^{\circ} \mathrm{C}$ and $32^{\circ} \mathrm{C}$ respectively with GWP of 150 to 1300 while its COP is close to those of blends L, M, and refrigerant R- 600a (1.1373; 1.2159). It also possesses improved flammability in comparison to blends $\mathrm{L}$ and $\mathrm{M}$ as well as refrigerant $\mathrm{R}-600 \mathrm{a}$ due to its higher mass composition of R-134a.

\section{CONCLUSIONS}

The aim of this research work is to develop blends within the stipulated limit of GWP as define by the European Union, and experimentally investigates their performance in a domestic vapour compression refrigeration system. Thus, the blends were formed as a mixture of R-134a and R-600a at ratios determine by Ali's model. The results obtained revealed that the blends had better performance and can each successfully serve as replacement for R-134a without changing: pipe thickness, compressor, cooling method and lubricant in the existing R-134a system, except that they are mildly flammable. The blend also offers more economic importance as $1 \mathrm{~kg}$ of it is cheaper compared to $1 \mathrm{~kg}$ of R-134a.

\section{REFERENCES}

[1] Susan, M. "Refrigerants, refrigeration cycles, and refrigeration systems", UPI Science, UK, 2011.

[2] Calm J.M., "Refrigerant Transitions....Again Moving Towards Sustainability," Proceedings of the ASHRAE/NIST Conference, Gaithersburg, MD, USA, Keynote Presentation, Oct. 2012.

[3] Thomas, L.J., Younghwan, K. and Jongchul, H. "Performance of novel low GWP refrigerants for AC and heating" Proceedings of International Conference on Air Conditioning and Refrigeration, ICACR, 2011, -00150.

[4] UNEP DTIE OzonAction - Protecting the Ozone Layer, Volume 1, Refrigerants, UNEP, 2010. 
[5] Dalkilic A.S., "Theoretical Analysis on the Prediction of Performance Coefficient of TwoStage Cascade Refrigeration System using Various Alternative Refrigerant," Journal of Thermal Science and Technology, 3, 2012, 67-70.

[6] Suguna, R.N. and Senthil, K.P. "Potential replacement to chlorofluorocarbon refrigerant- a review", Global Journal of Engineering Science and Research 1 (5), 2014, 45-49.

[7] Abasiryu T., Ayuba A., and Zira A.E., "Performance evaluation of some locally fabricated cookstoves in mubi, adamawa state, nigeria", Nigerian Journal of Technology, 35 (1), 2016, pp. 48-53

[8] Igboanugo A.C., Ajieh M.U., and Azi S.O, "Performance evaluation of a biomass stove using particulate matter and carbon monoxide emission from briquette and fuel wood", Nigerian Journal of Technology, 34 (3), 2015, pp. 484-494

[9] Hung P., "Next generation refrigerants: standards and climate policy implications of engineering constraints," ACEEE Summer Study on Energy Efficiency in Buildings, 1, 2010, pp. 282-294.

[10] Chavhan, S.P. and Mahajan, S.D. "A review of alternative to R-134a refrigerant in domestic refrigerator," International Journal of Emerging Technology and advanced Engineering, 3, 2013, pp. 356-359.

[11] Domanski, P.A. and Yashar, D. "Comparable performance evaluation of $\mathrm{HC}$ and $\mathrm{HFC}$ refrigerants in an optimized system," $7^{\text {th }} I I R$
Gustav Conference on Natural Working Fluids, Trondheim, Norway, 2006, pp. 1-15.

[12] AdegunI.K. and ObasaO.V. "Development of a dual purpose refrigeration system for domestic use," Nigerian Journal of Technology, 35 (4), 2016, pp. 814-824

[13] Wongwises, S. and Chimres, N. "Experimental study of hydrocarbon mixtures to replace HFC$134 \mathrm{a}$ in a domestic refrigerator," Energy Conversion and Management, 46, 2005, pp. 85100.

[14] Wongwise, S. Kamboon, A. and Orachon, B. "Experimental investigation of hydrocarbon mixtures to replace HFC-134a in an automotive air conditioning system," Energy Conversion and Management, 47, 2006, pp. 1644-1659.

[15] Khorshid, E., Alshiraan, B., Alsairafi, A., Alzemi, A. and Allahddad, A. Performance investigation on new refrigerant mixture. Proceedings of Modeling, Simulation and Applied Optimization (ICMSAO) $4^{\text {th }}$ International Conference, Kuala Lumpur, Malaysia. 2011, pp. 1-5.

[16] Austin N., Senthil K. P., and Kanthavelkumaran N., "Thermodynamic optimization of household refrigerator using propane -butane as mixed refrigerant," International Journal of Engineering Research and Applications, 2, 2012, pp. 268-271.

[17] Ali, R. "Calculating the global warming potential of refrigerant gas mixes," Ecometrica, 2, 2011, pp. $17-20$ 